\title{
Efficacy of Prothrombin Complex Concentrate versus Fresh Frozen Plasma in Patients with Bleeding in the Emergency Department
}

\author{
- B Burak Demirci, ๑ Abuzer Coskun \\ University of Health Sciences Turkey, Istanbul Bagcilar Training and Research Hospital, Clinic of Emergency Medicine, Istanbul, Turkey
}

\section{Abstract}

\begin{abstract}
Aim: It is important to determine which of the treatment options applied in the emergency department is more effective and usable in coagulation pathologies. In this study, we aimed to evaluate the efficacy and safety of fresh frozen plasma (FFP) and prothrombin complex concentrate (PCC), which are used in the treatment of high hemostasis parameters in the emergency department.
\end{abstract}

Methods: This retrospective study included 103 patients who were admitted to the emergency department between January 2019 and December 2020. All data were obtained from the hospital automation system. While the patients were divided into two groups (FFP-PCC) according to the treatment option they received, they were also divided into three groups (DED-RSH-ISH) according to hospitalization status. With this data, treatment efficacy and outcomes were analyzed.

Results: The mean age of 103 patients was $67.31 \pm 13.17$ years, with 58 (56\%) females and 45 (44\%) males. 51 (49.5\%) of the cases received FFP and 52 (50.5\%) PCC treatment. While the international normalized ratio (INR) 1 value before the treatment was $7.56 \pm 4.09$ and $2.42 \pm 1.01$ after the treatment in the FFP group, the INR1 value was $10.12 \pm 5.18$ and INR2 $1.95 \pm 0.71$ in the PCC group. The percentage of INR decrease was $60.28 \pm 19.76(\%)$ in the FFP group, and $73.41 \pm 17.42(\%)$ in the PCC group (p=0.001). In receiver operating characteristic curve analysis, the sensitivity and specificity of FFP and PCC decreased significantly in INR\%.

Conclusion: FFP is preferable in this regard to FFP because it is easier to apply, has a faster effect, and provides better values in coagulation parameters.

Keywords: Emergency departments, fresh frozen plasma, hemostasis, blood coagulation factors, prothrombin complex concentrates

\section{Introduction}

In the emergency department, abnormal bleeding can be seen in patients due to defective hemostasis mechanisms. In addition to drug use, conditions such as liver disease and kidney failure can increase the potential for abnormal bleeding (1). In recent years, there has been an increase in the number of patients admitted to the emergency department with warfarin-related complications. Warfarin is important for emergency physicians because it is associated with bleeding complications when the therapeutic range is exceeded and its interactions with drugs are frequent (2). The frequency of emergency department admissions as a result of developing complications is also mentioned. It is also stated that the risk of life-threatening or fatal bleeding is between $1-3 \%(3,4)$.
The International Normalized Ratio (INR) is used as a follow-up parameter for warfarin treatment effectiveness. These INR values reflect the extent of anticoagulation that minimizes the risk of serious bleeding while reducing morbidity from thromboembolic disease. For most indications, the INR range of 2-3 is used. Patients with high INR values, asymptomatic or with accompanying bleeding findings, are frequently evaluated in the emergency department $(5,6)$.

To achieve this, fresh frozen plasma (FFP) and prothrombin complex concentrates (PCC) are used today. Both have their advantages and disadvantages. FFP is plasma obtained by separating whole blood from erythrocytes and platelets and freezing within eight hours after collection. FFP is suitable for rapid replacement in

Address for Correspondence: Burak Demirci

University of Health Sciences Turkey, Istanbul Bagcilar Training and Research Hospital, Clinic of Emergency Medicine, Istanbul, Turkey

Phone: +90 (212) 4404000 E-mail: drburakdemirci@hotmail.com ORCID: orcid.org/0000-0001-6658-7260

Copyright 2022 by The Medical Bulletin of Istanbul Haseki Training and Research Hospital Received: 14.07.2021 Accepted: 23.11.2021 
multiple coagulation deficiencies such as hepatic failure, warfarin overdose, disseminated intravascular coagulation, and massive transfusion in patients with bleeding. While it has very positive effects when used by its indication, it can also lead to serious complications related to transfusion when used off-label (7). In addition, PCC can be given to patients with high INR to relieve symptoms or in cases where an urgent invasive procedure is required. The use of PCCs containing vitamin K-dependent coagulation factors is also recommended, especially in order to reverse the anticoagulant effect associated with the use of warfarin, due to its advantages such as rapid improvement in INR level, shorter administration time, and higher amount of factors than normal plasma (8-10).

It is seen that the use of PCC has become widespread, especially recently, and accordingly, studies conducted both in isolation and in the form of comparisons with FFP have increased. These studies include trauma or surgical process patients as well as emergency department patients. Both applications are used as treatment options for bleeding disorders, which are a very common reason for admission. Opinions are different about their supply, application times, and ability to provide the desired effectiveness, and the researches continue increasingly. This important and common issue has also encouraged us to work on which treatment is more appropriate (11-14).

In our study, we aimed to evaluate the effects of demographic characteristics, warfarin use, admission complaints, as well as the effects of FFP and PCC treatments on hemostasis values of patients with high INR levels in the emergency department.

\section{Methods}

\section{Compliance with Ethical Standards}

The study was carried out in the University of Health Sciences Turkey, Istanbul Bagcilar Training and Research Hospital Emergency Medicine Clinic, in accordance with the Helsinki Declaration rules, after the approval of the local ethics committee (decision date and number: 03.05.2021-190).

\section{Study Design and Population}

In this retrospective study, 103 patients who were older than 18 years old, had an INR value above 2, were treated with FFP or 4-factor PCC (Cofact ${ }^{\circledR}$, defined as the third generation) and did not meet any of our exclusion criteria, were admitted to the emergency department between January 2019 and December 2020 (58 women, 45 men; mean age $67.31 \pm 13.17$ years; range $24-88$ years, $56.3 \%$ women) were included.

Patients with known chronic liver and kidney disease, severe anemia, and malignancy, in addition to patients with deficiencies in admission and discharge hemostasis parameters and observation data, were excluded from the study.

Patients were divided into 2 groups according to whether they received FFP or PCC treatment in the emergency department. In addition, the patients were divided into 3 groups according to their discharge from the emergency department and hospitalization in the service and intensive care units.

Demographic information of patients from hospital records, comorbidity status, admission complaints, drug use, admission complaints, FFP or PCC treatment status, doses, type of complication if developed (within 24 hours), prothrombin time (PT) before and after treatment, activated Partial Thromboplastin Time (aPTT), INR values, and outcome patterns of the patients (admission, discharge, and death) were recorded. Pre-treatment values were recorded as aPTT1, PT1, INR1, and post-treatment values were recorded as aPTT2, PT2, INR2, according to the results of the sample taken at the $15^{\text {th }}$ minute after treatment. The percentages of decrease in INR were calculated and recorded as "decrease of INR\%".

\section{Statistical Analysis}

Version 21.0 (released in 2012 by IBM Corp.) of the IBM SPSS Statistics for Windows program (Armonk, NY: IBM Corp.) was used in the analysis. Continuous data were presented as mean standard deviation, while categorical data were presented as a percentage (\%). The Shapiro-Wilk test was used to investigate the conformity of the data to the normal distribution. In the comparison of normally distributed groups, an independent sample t-test analysis was used for cases with two groups. The Mann-Whitney U test was used for cases with two groups in the comparison of the groups that did not conform to the normal distribution. For the normally distributed variables, Pearson correlation coefficients were calculated to determine the direction and size of the relationship (correlation) between the variables. Chi-square analyses were used in the analysis of the created cross tables. A receiver operating characteristic (ROC) curve analysis was performed to determine the effectiveness of treatment options. A value of $p<0.05$ was considered significant for statistical significance.

\section{Results}

Of the 103 patients with elevated hemostasis parameters, 58 (56\%) were female and 45 (44\%) were male. Seventy-seven of the patients $(74.8 \%)$ had a history of warfarin use. $51(49.5 \%)$ of the patients received FFP and 52 (50.5\%) PCC treatment. While 47 (45.6\%) patients applied due to hemorrhage, this was followed by 13 $(12.6 \%)$ patients for laboratory follow-up. No treatmentrelated complications developed in any of the patients. Of 
the patients with bleeding, 8 (7.8\%) had hematemesis, 9 $(8.7 \%)$ had melena, 6 (5.9\%) had hematochezia, and 8 (7.8\%) had hematuria (Table 1).

The mean age of 103 patients who received FFP or PCC treatment was $67.31 \pm 13.17$ years. INR2 values were $2.42 \pm 1.01$ in the FFP group and $1.95 \pm 0.71$ in the PCC group. The correlation of recorded PT and INR values with applied treatment options was significant. The percentages of decrease in INR after treatment were $66.91 \pm 19.66(\%)$ in all groups, 60.28 $\pm 19.76(\%)$ in the FFP group, and $73.41 \pm 17.42(\%)$ in the PCC group $(p=0.001$, Table 2$)$.

According to the hospitalization status of the patients; 47 (45.6\%) were discharged from the emergency department (DED), 49 (47.6\%) were relevant service hospitalizations (RSH), and 7 (6.8\%) were in the intensive care hospitalization group. None of the patients presenting with altered consciousness could be discharged from the emergency department. In the DED group, 20 (42.6\%) patients received FFP and 27 (57.4\%) patients received PCC treatment (Table 3).

In the correlation analysis of the applied treatment option with the variables, there was a strong positive correlation between the decrease in INR\% and the treatment option ( $p=0.001$, Table 4).

In the ROC curve analysis of the INR \% change of FFP, the area under curve (AUC): 0.286 , with a $95 \%$ confidence

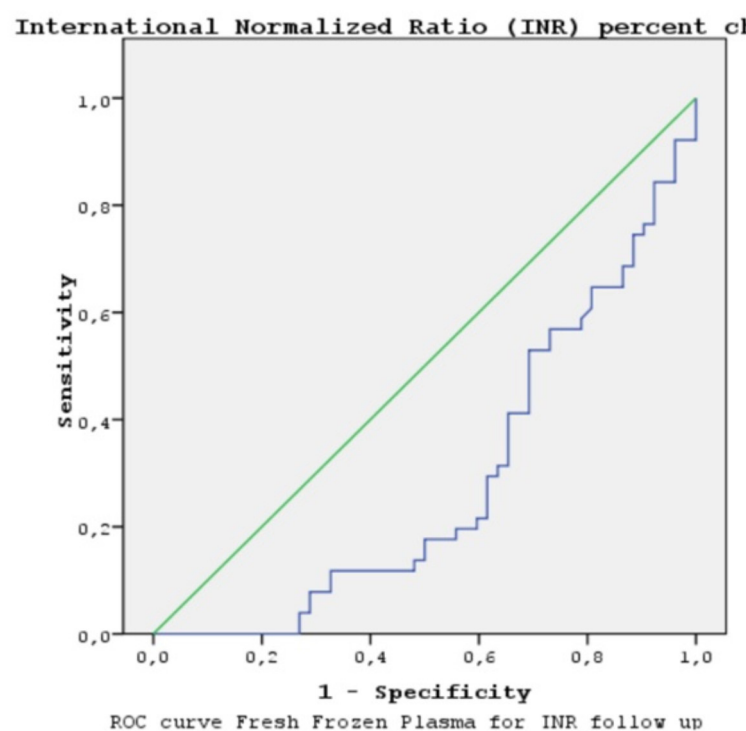

Figure 1. ROC curve analysis of FFP in INR change ROC curve analysis of INR change of FFP; area under curve $0.286, \% 95$ confidence interval $0.187-0.385$, sensitivity: $86.5 \%$, specificity: $64.7 \%, p=0.001$

PCC: Prothrombin complex concentrate, INR: International normalized ratio, FFP: Fresh frozen plasma interval $(\mathrm{Cl})$ of $0.187-0.385$, sensitivity: $86.5 \%$, specificity: $64.7 \%$, ( $p=0.001$ ) (Figure 1). In the ROC curve analysis of PCC \% change in INR; AUC: 0.714, 95\% Cl: 0.615-0.813, sensitivity: $96.2 \%$, specificity: $88.2 \%$, $(p=0.001)$ (Figure 2 ). In addition, the distribution of the percent decrease in INR of FFP and PCC used in the treatment is given in Figure 3.

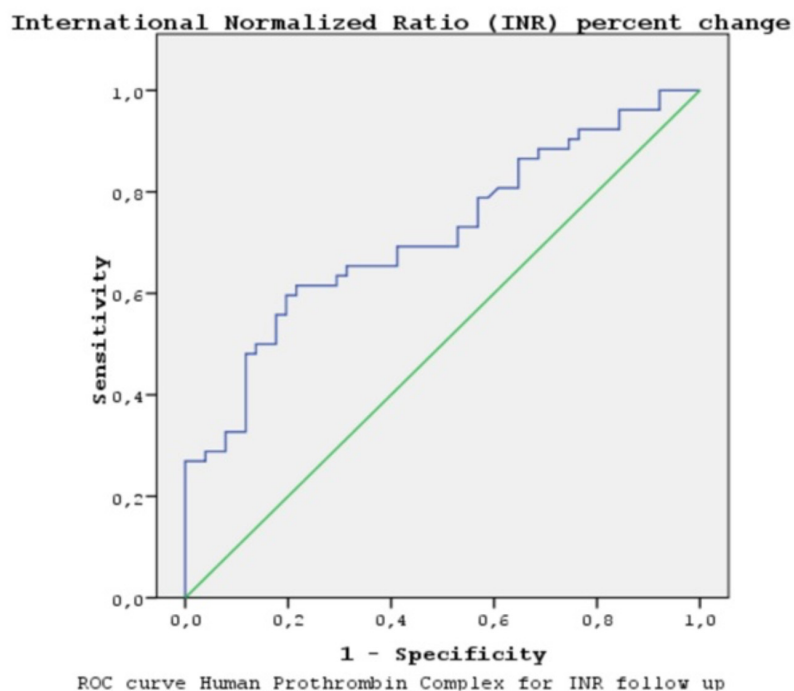

Figure 2. ROC curve analysis of PCC in INR change ROC curve analysis of PCC's INR change; area under curve $0.714, \% 95$ confidence interval $0.615-0.813$, sensitivity: $96.2 \%$, specificity: $88.2 \%, p=0.001$

PCC: Prothrombin complex concentrate, INR: International normalized ratio, FFP: Fresh frozen plasma

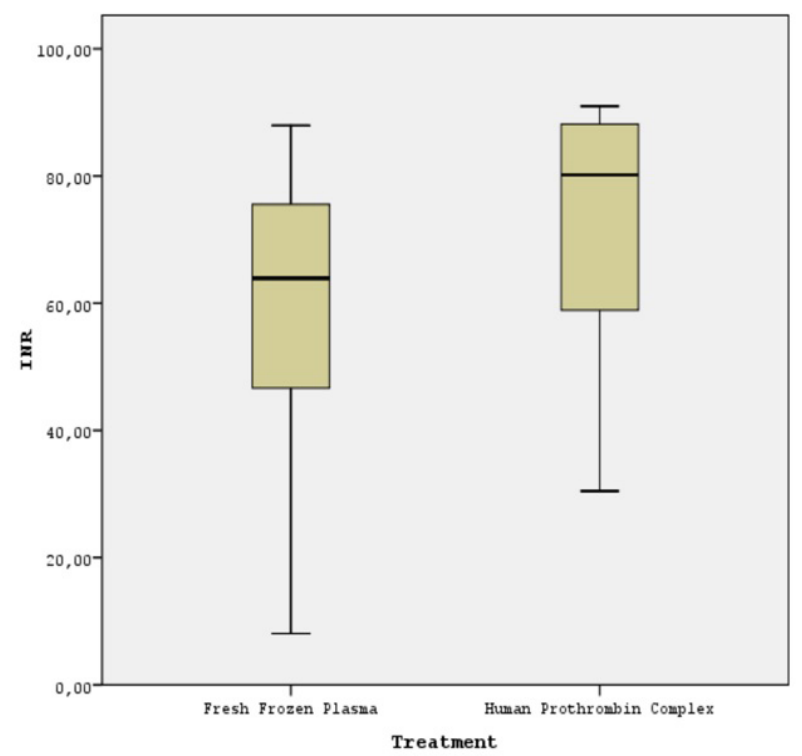

Figure. 3 Percentage of reduction in INR compared to FFP and PCC used in the treatment

PCC: Prothrombin complex concentrate, INR: International normalized ratio, FFP: Fresh frozen plasma 


\begin{tabular}{|c|c|c|c|c|}
\hline \multicolumn{5}{|l|}{ High INR treatment } \\
\hline & & \begin{tabular}{|l} 
FFP \\
n (\%) \\
$51(49.5 \%)$
\end{tabular} & $\begin{array}{l}\text { PCC } \\
\text { n (\%) } \\
52(50.5 \%)\end{array}$ & $\begin{array}{l}\text { ALL } \\
\text { n (\%) } \\
103(100 \%)\end{array}$ \\
\hline \multirow{2}{*}{ Gender } & Female & $32(62.7 \%)$ & $26(50 \%)$ & $58(56.3 \%)$ \\
\hline & Male & $19(37.3 \%)$ & $26(50 \%)$ & $45(43.7 \%)$ \\
\hline \multirow{2}{*}{ Use of coumadin } & No & $12(23.5 \%)$ & $14(26.9 \%)$ & $26(25.2 \%)$ \\
\hline & Yes & $39(76.5 \%)$ & $38(73.1 \%)$ & $77(74.8 \%)$ \\
\hline \multirow{8}{*}{ Complaint } & For analysis & $7(13.7 \%)$ & $6(11.5 \%)$ & $13(12.6 \%)$ \\
\hline & Hemorrhage & $25(49.0 \%)$ & $22(42.3 \%)$ & $47(45.6 \%)$ \\
\hline & Abdominal pain & $7(13.7 \%)$ & $2(3.8 \%)$ & $9(8.7 \%)$ \\
\hline & Nausea-vomiting & $5(9.8 \%)$ & $6(11.5 \%)$ & $11(10.7 \%)$ \\
\hline & Chest pain & $4(7.8 \%)$ & $2(3.8 \%)$ & $6(5.8 \%)$ \\
\hline & Shortness of breath & $2(3.9 \%)$ & $4(7.7 \%)$ & $6(5.8 \%)$ \\
\hline & Altered consciousness & $1(2.0 \%)$ & $2(3.8 \%)$ & $3(2.9 \%)$ \\
\hline & Bad general condition & $0(0 \%)$ & $8(15.4 \%)$ & $8(7.8 \%)$ \\
\hline \multirow{11}{*}{ Hemorrhage } & No & $26(51.0 \%)$ & $30(57.7 \%)$ & $56(54.5 \%)$ \\
\hline & Hematemesis & $7(13.8 \%)$ & $1(1.9 \%)$ & $8(7.8 \%)$ \\
\hline & Melena & $4(7.8 \%)$ & $5(9.8 \%)$ & $9(8.7 \%)$ \\
\hline & Hematochezia & $3(5.9 \%)$ & $3(5.8 \%)$ & $6(5.9 \%)$ \\
\hline & Hematuria & $4(7.8 \%)$ & $4(7.6 \%)$ & $8(7.8 \%)$ \\
\hline & Cranial & $2(3.9 \%)$ & $2(3.8 \%)$ & $4(3.9 \%)$ \\
\hline & Vaginal & $3(5.9 \%)$ & $1(1.9 \%)$ & $4(3.9 \%)$ \\
\hline & Dermal & $2(3.9 \%)$ & $3(5.8 \%)$ & $5(4.8 \%)$ \\
\hline & Articulation & $0(0 \%)$ & $1(1.9 \%)$ & $1(0.9 \%)$ \\
\hline & Eye & $0(0 \%)$ & $1(1.9 \%)$ & 1 (0.9\%) \\
\hline & Nasal & $0(0 \%)$ & $1(1.9 \%)$ & $1(0.9 \%)$ \\
\hline \multirow{2}{*}{ Complication } & No & $51(100 \%)$ & $52(100 \%)$ & $103(100 \%)$ \\
\hline & Yes & $0(0 \%)$ & $0(0 \%)$ & $0(0 \%)$ \\
\hline
\end{tabular}

\section{Table 2. Relationship of treatment options with other variables}

\section{High INR treatment}

\begin{tabular}{|l|l|l|l|l|} 
& FFP & PCC & ALL & p-value \\
\hline Age (year) & Mean \pm SD & Mean \pm SD & Mean \pm SD & \\
\hline APTT-1 (sec) & $67.84 \pm 13.22$ & $66.79 \pm 13.23$ & $67.31 \pm 13.17$ & 0.670 \\
\hline PT-1 (sec) & $83.49 \pm 37.23$ & $80.44 \pm 36.45$ & $81.95 \pm 36.69$ & 0.605 \\
\hline INR-1 & $89.29 \pm 48.35$ & $113.45 \pm 58.39$ & $101.49 \pm 54.75$ & $\mathbf{0 . 0 2 8}$ \\
\hline APTT-2 (sec) & $7.56 \pm 4.09$ & $10.12 \pm 5.18$ & $8.85 \pm 4.83$ & $\mathbf{0 . 0 0 9}^{*}$ \\
\hline PT-2 (sec) & $49.47 \pm 16.55$ & $42.98 \pm 15.65$ & $46.19 \pm 16.35$ & $\mathbf{0 . 0 1 7}^{*}$ \\
\hline INR-2 & $30.34 \pm 12.35$ & $24.07 \pm 9.34$ & $27.17 \pm 11.33$ & $\mathbf{0 . 0 0 5}^{*}$ \\
\hline Decrease of INR (\%) & $2.42 \pm 1.01$ & $1.95 \pm 0.71$ & $2.18 \pm 0.90$ & $\mathbf{0 . 0 2 3}^{*}$ \\
\hline PCC: Por & $60.28 \pm 19.76$ & $73.41 \pm 17.42$ & $66.91 \pm 19.66$ & $\mathbf{0 . 0 0 1}^{*}$ \\
\hline
\end{tabular}

PCC: Prothrombin complex concentrate FFP: Fresh frozen plasma, ALL: All patients, APTT: Activated partial thromboplastin time, PT: Prothrombin time, INR: International normalized ratio, sec: Second, SD: Standard deviation

*:Mann-Whitney U test, $\mathrm{p}$-value of $<0.05$ was considered statistically significant 


\begin{tabular}{|c|c|c|c|c|}
\hline \multicolumn{5}{|l|}{ Hospitalization } \\
\hline & & $\begin{array}{l}\text { DED } \\
n(\%) \\
47(45.6 \%)\end{array}$ & $\begin{array}{l}\text { RSH } \\
\text { n (\%) } \\
49(47.6 \%)\end{array}$ & \begin{tabular}{|l|} 
ICH \\
n (\%) \\
$7(6.8 \%)$ \\
\end{tabular} \\
\hline \multirow{2}{*}{ Gender } & Female & $26(55.3 \%)$ & $28(57.1 \%)$ & $4(57.1 \%)$ \\
\hline & Male & $21(44.7 \%)$ & $21(42.9 \%)$ & $3(42.9 \%)$ \\
\hline \multirow{2}{*}{ Use of coumadin } & No & $8(17 \%)$ & $16(32.7 \%)$ & $2(28.6 \%)$ \\
\hline & Yes & $39(83 \%)$ & $33(67.3 \%)$ & $5(71.4 \%)$ \\
\hline \multirow{8}{*}{ Complaint } & For analysis & $10(21.3 \%)$ & $3(6.1 \%)$ & $0(0 \%)$ \\
\hline & Hemorrhage & $18(38.3 \%)$ & $28(57.1 \%)$ & $1(14.3 \%)$ \\
\hline & Abdominal pain & $5(10.6 \%)$ & $4(8.2 \%)$ & $0(0 \%)$ \\
\hline & Nausea-vomiting & $7(14.9 \%)$ & $4(8.2 \%)$ & $0(0 \%)$ \\
\hline & Chest pain & $4(8.5 \%)$ & $2(4.1 \%)$ & $0(0 \%)$ \\
\hline & Shortness of breath & $2(4.3 \%)$ & $2(4.1 \%)$ & $2(28.6 \%)$ \\
\hline & Altered consciousness & $0(0 \%)$ & $2(4.1 \%)$ & $1(14.3 \%)$ \\
\hline & Bad general condition & $1(2.1 \%)$ & $4(8.2 \%)$ & $3(42.9 \%)$ \\
\hline \multirow{2}{*}{ Treatment } & FFP & $20(42.6 \%)$ & $27(55.1 \%)$ & $4(57.1 \%)$ \\
\hline & PCC & $27(57.4 \%)$ & $22(44.9 \%)$ & $3(42.9 \%)$ \\
\hline
\end{tabular}

\section{Discussion}

Today, cases who present with bleeding or other complaints in emergency departments and who have high hemostasis parameters are frequently seen. Although there are partial increases due to metabolic reasons, serious elevations are also detected, especially due to the use of warfarin. The clinical spectrum of patients with elevated hemostasis parameters varies, and it is usually up to emergency clinicians to ensure that the values are in the ideal range. With correct and rapid treatment, it is possible to reduce the mortality and morbidity of patients. FFP and PCC, which are among the treatment modalities applied in an emergency, create a preferred position for the clinician.

FFP is suitable for rapid replacement in multiple coagulation deficiencies such as hepatic failure, warfarin overdose, disseminated intravascular coagulation, and massive transfusion in bleeding patients. FFP can also be used when bleeding is due to a deficiency of coagulation factors. Response to FFP treatment can be monitored by performing coagulation system examinations such as PT, INR, and aPTT (15).

PCC, whose preparations consist of human plasma; contains FII, FVII, FIX, and FX components, is also used in anticoagulant therapy with proven effectiveness. Studies show that PCC offers us not only an effective but also a safe treatment option $(16,17)$. Studies have shown that four-factor PCCs are more effective than three-factor PCCs in the emergency department, but there is no difference with FFP in terms of effectiveness and side effects (18).

\begin{tabular}{|c|c|c|}
\hline \multirow{2}{*}{ Variables } & \multicolumn{2}{|c|}{ Treatmant option (FFP-PCC) } \\
\hline & $r$ & $p$ \\
\hline Gender & 0.128 & 0.196 \\
\hline Age & -0.042 & 0.672 \\
\hline Coumadin use & -0.039 & 0.695 \\
\hline Complaint & 0.166 & 0.094 \\
\hline Hospitalization & -0.126 & 0.205 \\
\hline APTT-1 (sec) & -0.051 & 0.607 \\
\hline PT-1 (sec) & 0.217 & $0.028^{*}$ \\
\hline INR-1 & 0.260 & $0.008^{*}$ \\
\hline APTT-2 (sec) & -0.235 & $0.017^{*}$ \\
\hline PT-2 (sec) & -0.279 & $0.004^{*}$ \\
\hline INR-2 & -0.225 & $0.022^{*}$ \\
\hline Decrease of INR (\%) & 0.371 & $0.001^{*}$ \\
\hline \multicolumn{3}{|c|}{$\begin{array}{l}\text { PCC: Prothrombin complex concentrate, FFP: Fresh frozen plasma, APTT: } \\
\text { Activated partial thromboplastin time, PT: Prothrombin time, INR: International } \\
\text { normalized ratio, sec: Second } \\
* \text { : Pearson correlation test, p-value of }<0.05 \text { was considered statistically } \\
\text { significant }\end{array}$} \\
\hline
\end{tabular}

There are studies evaluating the efficacy, side effects, and prognosis of the use of PCC and FFP in different cases and circumstances. In the study of Karkouti et al. (19), the efficacy of treatment in bleeding during cardiac surgery was investigated, and it was shown that the use of PCC is appropriate because it significantly reduces the need for FFP and can have a hemostatic advantage without increasing the occurrence of adverse events. In trauma patients, a 
resuscitation strategy using both PCC and FFP transfusion was associated with reduced mortality compared with a resuscitation strategy involving FFP alone. In addition, PCC reduced the need for RBC transfusions compared to treatment strategies without PCC (20). Although the use of PCC is considered an effective and recommended practice in general, On the other hand, there are researchers who argue that the use of PCC should be avoided in all patients with high INR values caused by vitamin $\mathrm{K}$ antagonists and that it can only be used in cases requiring emergency surgery due to serious, life-threatening bleeding (21).

The most important factor for bleeding risk is the INR level, which is above the treatment levels. It has been stated that when the INR level rises from 2-3 to 3-4.5, the risk of bleeding increases 2 times, and when it is between 4.5-6, it increases 4 times. Every 0.5 increase in INR levels increases the risk of major bleeding by 1.43 (22). In a study by Kaya et al. (23) in which they evaluated the use of PCC in an emergency department, the median INR value of the patients was 8.96. In our study, the median INR value of the patients who applied similarly to other studies was $8.85 \pm 4.83$ and $77(74.8 \%)$ were patients using warfarin for different reasons.

Elderly patients are more susceptible to anticoagulant effects and bleeding than younger patients. In cases over 40 years of age using warfarin, it has been shown that there is a $46 \%$ increase in the rate of major bleeding with every 10 years of age. The presence of additional diseases also contributes to this situation (22). Apart from drug efficacy in studies, the condition and comorbid diseases are also important because most of the patients are elderly. It is noteworthy that patients who applied to the emergency department used warfarin, and had high INR values were mostly older. In a similar study, Sarode et al. (4) found the mean age to be 68 years, whereas Barillari et al. (24) reported 76 years. The mean age of the patients in our study was 67 years, which was correlated with the others. Although some studies did not report significant differences in the gender distribution of patients, Keren et al. (25). In their study, the rate of female patients was $56 \%$, similar to our study (26). We think that the important reason for the slightly higher female gender is the incidence of atrial fibrillation and the use of warfarin.

When the complaints of patients who were anticoagulated with warfarin were evaluated, it was shown that the most frequently affected system was the gastrointestinal system (38.5\%) (27). In the study conducted by Sayhan et al. (28), it was seen that $16.9 \%$ of the patients presented with mostly gastrointestinal bleeding. In our study, bleeding was detected in 47 $(45.6 \%)$ of all patients, and gastrointestinal system bleeding was found in 23 (31.4\%) of them. In addition to the complaints at presentation, nausea and vomiting were present in $11(10.7 \%)$ of the patients. The presence of nausea and vomiting, especially in patients using warfarin, should also suggest an elevated INR.

As a general rule, patients with severe or lifethreatening bleeding require a rapid, complete reversal of the effect of warfarin; patients with no bleeding or minor bleeding, especially if the risk of thrombosis is high, can only be followed by discontinuing warfarin. International guidelines recommend the use of PCCs instead of FFP for reversing acute vitamin $\mathrm{K}$ antagonism in clinical bleeding $(29,30)$. The risk of bleeding is greatest in the initial phase of treatment. Bleeding rates per year in randomized studies are between 1 and 3\%. The most dangerous bleeding for most patients is intracerebral hemorrhage, which can be fatal or cause permanent neurological deficits (31). In the study by Steiner et al. (32), four-factor PCC was found to be superior to FFP in normalizing INR. It has been observed that faster INR normalization leads to smaller hematoma development. The results support the use of PCC instead of FFP in intracranial hemorrhage (32). In our study, PCC was applied to two of the four patients with intracranial hemorrhage, and it was found that success was achieved in terms of more appropriate reference values in INR normalization.

Life-threatening bleeding due to an overdose is relatively low. In his treatment, firstly, stopping warfarin and controlling it by transfusion in the emergency resulted in low hospitalization rates. In some studies, it is recommended that patients in this situation be treated by emergency services and called for necessary controls in order not to increase the cost of the hospital further (33). In our study, 47 (45.6\%) patients were successfully treated in the emergency room and discharged. Appropriate dosing was performed, and they were called for control.

PCC was found to be more effective than FFP in normalizing INR and facilitating coagulation. A study of patients with mechanical heart valve disease using warfarin showed that more patients in the PCC group than in the FFP group achieved the ideal INR. The mean INR value before the PCC application was $4.02 \pm 1.07$ and the mean INR value before the FFP application was 4.88 1 1.3. However, the mean INR value decreased to 2.51 in the first 48 hours after PCC application (34). In another study, while the mean INR value before PCC was 2.92 (2.54), the mean INR value after PCC was reported as 1.47 (0.44). The mean difference was 1.54 (2.89), which reached statistical significance $(p=0.005)$ (35). In our study, control INR values were $2.42 \pm 1.01$ in the FFP group and $1.95 \pm 0.71$ in the PCC group. In addition, the percentage decrease in INR was $60.28 \pm 19.76(\%)$ in the FFP group and $73.41 \pm 17.42(\%)$ in the PCC group. There 
were no complications related to the application in both groups. The results of our study showed ideal and safe results in the same direction as other studies in terms of PCC's efficiency and bringing hemostasis parameters to the ideal range.

Compared to the FFP application, fewer thrombotic complications and transfusion reactions were listed as reasons supporting the use of PCC in cases with warfarin overdose. Cruz et al. reported $7.1 \%$ thrombotic complications with PCC given after warfarin use (36). In a study using four-factor PCC, the thrombotic complication rate was reported as 1.8\% (95\% Cl 1.0-3.0) (37). In addition, it is recommended to use PCC by considering the benefitharm balance (26). In our study, no thromboembolic event was detected in any of our cases. The fact that long-term clinical follow-ups were not performed or cases with earlyterm mortality could not be evaluated for complications may have affected the results.

In a meta-analysis (37), the overall mortality rate due to warfarin overdose was reported as $10.6 \%(95 \% \mathrm{Cl}$ 5.9-16.6\%). In patients who had PCC indications after warfarin use, 30-day mortality was reported as $22.9 \%$ (36). In our study, no mortality was observed during follow-up and treatment in the emergency department. This may show that the treatments applied do not have any mortal complications and that the treatment process has developed quite positively in terms of high hemostasis parameters today.

\section{Study Limitations}

The retrospective nature of the study was an important limitation. In addition, the limitations of the study are that it is a single-center and the factors that will affect mortality after PCC treatment (additional diseases of the cases, additional drugs used, surgical applications for bleeding control, additional medical treatments given during follow-up). Despite these limitations, clear and efficient analysis of numerical laboratory parameters before and after treatment, and objective interpretation of treatment efficacy are the strengths of the study. In addition, we believe that it contributes positively to the literature in terms of giving an idea about the choice of treatment in these cases, which are frequently encountered and treated in emergency services.

\section{Conclusion}

Both FFP and PCC treatments can be safely applied to patients with elevated hemostasis parameters in emergency departments. Recent studies and the result of our study show that PCC is preferable to FFP because it is easier to apply, acts faster, and provides more ideal coagulation parameter levels. Further studies are needed to reveal the cost, efficacy, and safety dimensions of both treatment options.

\section{Ethics}

Ethics Committee Approval: The study was carried out in the University of Health Sciences Turkey, Istanbul Bagcilar Training and Research Hospital Emergency Medicine Clinic, in accordance with the Helsinki Declaration rules, after the approval of the local ethics committee (decision date and number: 03.05.2021-190).

Informed Consent: Retrospective study.

\section{Authorship Contributions}

Concept: B.D., Design: B.D., A.C., Data Collection or Processing: B.D., Analysis or Interpretation: B.D., Literature Search: B.D., A.C., Writing: B.D., A.C., Supervision and Revision: B.D., A.C.

Conflict of Interest: No conflict of interest was declared by the authors.

Financial Disclosure: The authors declared that this study received no financial support.

\section{References}

1. Greaves M, Watson HG. Approach to the diagnosis and management of mild bleeding disorders. J Thromb Haemost 2007;5:167-74.

2. Altunbaş G, Ercan S, Davutoğlu V, Al B. Overview of Warfarin Treatment and Answers to Questions. Eurasian J Emerg Med 2013; 12:38-42.

3. Chapman SA, Irwin ED, Beal AL, Kulinski NM, Hutson KE, Thorson MA. Prothrombin complex concentrate versus standard therapies for INR reversal in trauma patients receiving warfarin. Ann Pharmacother 2011;45:869-75.

4. Sarode R, Milling TJ Jr, Refaai MA, et al. Efficacy and safety of a 4-factor prothrombin complex concentrate in patients on vitamin $\mathrm{K}$ antagonists presenting with major bleeding: a randomized, plasma-controlled, phase IIlb study. Circulation 2013;128:1234-43.

5. Hylek EM, Held C, Alexander JH, et al. Major bleeding in patients with atrial fibrillation receiving apixaban or warfarin: The ARISTOTLE Trial (Apixaban for Reduction in Stroke and Other Thromboembolic Events in Atrial Fibrillation): Predictors, Characteristics, and Clinical Outcomes. J Am Coll Cardiol 2014;63:2141-7.

6. Morgan CL, McEwan P, Tukiendorf A, Robinson PA, Clemens A, Plumb JM. Warfarin treatment in patients with atrial fibrillation: observing outcomes associated with varying levels of INR control. Thromb Res 2009;124:37-41.

7. Ozgonenel B, O'Malley B, Krishen P, Eisenbrey AB. Warfarin reversal emerging as the major indication for fresh frozen plasma use at a tertiary care hospital. Am J Hematol 2007;82:1091-4.

8. Gage BF, Eby C, Johnson JA, et al. Use of pharmacogenetic and clinical factors to predict the therapeutic dose of warfarin. Clin Pharmacol Ther 2008;84:326-31.

9. Carlquist JF, Horne BD, Mower C, et al. An evaluation of nine genetic variants related to metabolism and mechanism of action of warfarin as applied to stable dose prediction. J Thromb Thrombolysis 2010;30:358-64. 
10. Tanaka KA, Key NS, Levy JH. Blood coagulation: hemostasis and thrombin regulation. Anesth Analg 2009;108:1433-46.

11. Green L, Roberts N, Cooper J, et al. Prothrombin complex concentrate vs. fresh frozen plasma in adult patients undergoing heart surgery - a pilot randomised controlled trial (PROPHESY trial). Anaesthesia 2021;76:892-901.

12. Kao TW, Lee YC, Chang HT. Prothrombin Complex Concentrate for Trauma Induced Coagulopathy: A Systematic Review and Meta-Analysis. J Acute Med 2021;11:81-9.

13. Bouzat $P$, Bosson JL, David JS, et al. Four-factor prothrombin complex concentrate to reduce allogenic blood product transfusion in patients with major trauma, the PROCOAG trial: study protocol for a randomized multicenter doubleblind superiority study. Trials 2021;22:634.

14. Naeem Z, Allan S, Hernandez A, Galanakis DK, Singer AJ. Clinical utilization of four-factor prothrombin complex concentrate: a retrospective single center study. Clin Exp Emerg Med 2021;8:75-81.

15. Bianco C. Choice of human plasma preparations for transfusion. Transfus Med Rev 1999;13:84-8.

16. Makris M, Van Veen JJ. Three or four factor prothrombin complex concentrate for emergency anticoagulation reversal?. Blood Transfus 2011;9:117-9.

17. Ansell J, Hirsh J, Poller L, Bussey H, Jacobson A, Hylek E. The pharmacology and management of the vitamin K antagonists: the Seventh ACCP Conference on Antithrombotic and Thrombolytic Therapy. Chest 2004;126(Suppl 3):204-33.

18. Leissinger CA, Blatt PM, Hoots WK, Ewenstein B. Role of prothrombin complex concentrates in reversing warfarin anticoagulation: a review of the literature. Am J Hematol 2008;83:137-43.

19. Karkouti K, Bartoszko J, Grewal D, et al. Comparison of 4-Factor Prothrombin Complex Concentrate With Frozen Plasma for Management of Hemorrhage During and After Cardiac Surgery: A Randomized Pilot Trial. JAMA Netw Open 2021;4:e213936.

20. van den Brink DP, Wirtz MR, Neto AS, et al. Effectiveness of prothrombin complex concentrate for the treatment of bleeding: A systematic review and meta-analysis. J Thromb Haemost 2020;18:2457-67.

21. Sayhan MB, Salt Ö, Demir AM. Prothrombin Complex Concentrates in Life-Threatening Bleeding. Balkan Med J 2016;33:712-3.

22. Baker RI, Coughlin PB, Gallus AS, et al. Warfarin reversal: consensus guidelines, on behalf of the Australasian Society of Thrombosis and Haemostasis. Med J Aust 2004;181:492-7.

23. Kaya FB, Ozakin E, Yüksel GC, Karakılıç ME, Kaya S, Çanakçı ME. Use Of Prothrombın Complex Concentrate In The Emergency Department For Cases With Warfarin Overdose: A Retrospective Study. Ankara Med J 2020;4:1071-81.

24. Barillari G, Pasca S, Barillari A, De Angelis V. Emergency reversal of anticoagulation: from theory to real use of prothrombin complex concentrates. A retrospective Italian experience. Blood Transfus 2012;10:87-94.
25. Keren F, Simşek ET, Balçık Öş, Koşar A. To use prothrombin complex concentrate for reversing the anticoagulant effect depending on warfarin: A single-center study. New Med,ical Journal 2014;31:172. https://app.trdizin.gov.tr/publication/ paper/detail/TVRZMU5UTTFOUT09

26. Marcos-Jubilar M, García Erce JA, Martínez-Calle N, Páramo JA, Martínez Virto A, Quintana-Díaz M. Safety and effectiveness of a prothrombin complex concentrate in approved and offlabel indications. Transfus Med 2019;29:268-74.

27. Eroğlu S, Denizbaşı A, Özpolat Ç, Akoğlu H, Onur ÖE, Akoğlu EÜ. The Investigation of the Relation Between INR Levels and Risk of Complication in Patients with a History of Warfarin use. Marmara Med J 2015;25:138-42.

28. Sayhan MB, Oğuz S, Yüksel V, Hüseyin S, ayhan ES, Yağcl G. The Analysis of Patients Admitted to the Emergency Department Due to Complications Related to Warfarin Treatment. Eurasian J Emerg Med 2014;13:194-8.

29. Cross-sectional guidelines for therapy with blood components and plasma derivatives: Chapter 7 Procoagulators. Transfus Med Hemother 2009;36:419-36. DOI: 10.1159/000268063

30. O'Shaughnessy DF, Atterbury C, Bolton Maggs P, et al. Guidelines for the use of fresh-frozen plasma, cryoprecipitate and cryosupernatant. Br J Haematol 2004;126:11-28.

31. Holbrook A, Schulman S, Witt DM, et al. Evidence-based management of anticoagulant therapy: Antithrombotic Therapy and Prevention of Thrombosis, 9th ed: American College of Chest Physicians Evidence-Based Clinical Practice Guidelines. Chest 2012;141(Suppl 2):152-84.

32. Steiner $T$, Poli $S$, Griebe $M$, et al. Fresh frozen plasma versus prothrombin complex concentrate in patients with intracranial haemorrhage related to vitamin $\mathrm{K}$ antagonists (INCH): a randomised trial. Lancet Neurol 2016;15:566-73.

33. Nelson WW, Wang L, Baser O, Damaraju CV, Schein JR. Outof-range international normalized ratio values and healthcare cost among new warfarin patients with non-valvular atrial fibrillation. J Med Econ 2015;18:333-40.

34. Fariborz Farsad B, Golpira R, Najafi H, et al. Comparison between Prothrombin Complex Concentrate (PCC) and Fresh Frozen Plasma (FFP) for the Urgent Reversal of Warfarin in Patients with Mechanical Heart Valves in a Tertiary Care Cardiac Center. Iran J Pharm Res 2015;14:877-85.

35. Tanaka KA, Szlam F. Treatment of massive bleeding with prothrombin complex concentrate: argument for. J Thromb Haemost 2010;8:2589-91.

36. Cruz JL, Moss MC, Chen SL, Hansen KM, Amerine LB. Retrospective evaluation of the clinical use of prothrombin complex concentrate for the reversal of anticoagulation with vitamin $\mathrm{K}$ antagonists. Blood Coagul Fibrinolysis 2015;26:378-82.

37. Dentali F, Marchesi C, Giorgi, et al. Safety of prothrombin complex concentrates for rapid anticoagulation reversal of vitamin $\mathrm{K}$ antagonists. A meta-analysis. Thromb Haemost 2011;106:429-38. 